\title{
Past as Prelude: Lessons for the Future Acquired from 50 Years on the Edge
}

\author{
Steven F. Warren, Ph.D. \\ Director, Schiefelbusch Institute for Life Span Studies \\ University of Kansas
}

S tarting a multi-disciplinary research center is a complex endeavor. Nevertheless, a large number of such centers have been created across this country and throughout the world in response to a range of scientific and technological advances and generous increases in public and private funding. Although the scientific advances have continued and even accelerated by many measures during this period, federal funding for research has leveled off and even decreased over the past several years. Consequently a question that faces many center directors as well as university leadership in general is how to maintain and even expand these initiatives in the current funding climate. What are the secrets to long-term success that span a wide range of funding climates?

I am fortunate to direct a multidisciplinary research institute with a relatively long history - well over 50 years in terms of its "modern era" and over 80 years since its initial inception. What lessons for research centers in general can be gleaned from our history? I believe that there are indeed some important lessons of direct relevance to the center directors and university leaders who face the challenges of sustaining both older and newer programs. The purpose of this paper is to briefly discuss some lessons or principles that I believe can make a real difference. I first provide a brief description of the Schiefelbusch Institute for Life Span Studies - the program I direct - because its history is the basis for most of the lessons I've learned. Then I suggest some general recommendations for university leaders and research administrators based on what I believe to be dangerous illusions that can harm research center programs in general. Finally, I conclude with a discussion of specific recommendations.

\section{The Life Span Institute}

The Schiefelbusch Institute for Life Span Studies (LSI) traces its roots to an act of the Kansas Legislature in 1921 (see Schiefelbusch and Schroeder, 2006, for a full history of this program). The visionary effort established a "bureau of child research" to be housed at the university. The seeds for the program in its present form were planted when

Dick Schiefelbusch became the director 
in the mid-1950s. The program morphed into it present form in 1990 under the directorship of Steve Schroeder. The mission of the LSI is to create solutions to problems of human and community development, disability, and aging. At present it is both the oldest and largest research institute at KU with over 130 investigators from more than 20 academic discipline conducting at any one time between 100 and 110 externally funded research projects supported by more than 20 million dollars in direct costs and generating more than 3.5 million in indirect costs annually. These projects are located at the main campus in Lawrence, the medical center campus in Kansas City (KUMC), the Juniper Gardens Children's Project in Kansas City, and the Parsons Research Center in Parsons. The largest source of funding comes from the National Institutes of Health (principally NICHD and NIDCD) with the U.S. Department of Education providing the second largest amount.

The funding history of Life Span Institute since 1960 is represented in the figure below. There are three bar graphs represented - one for university support provided to fund core personal and infrastructure for the institute, one for external awards and one for indirect costs.

\section{LSI Funding History: State Allocations and Grant Dollars - By Fiscal Year}

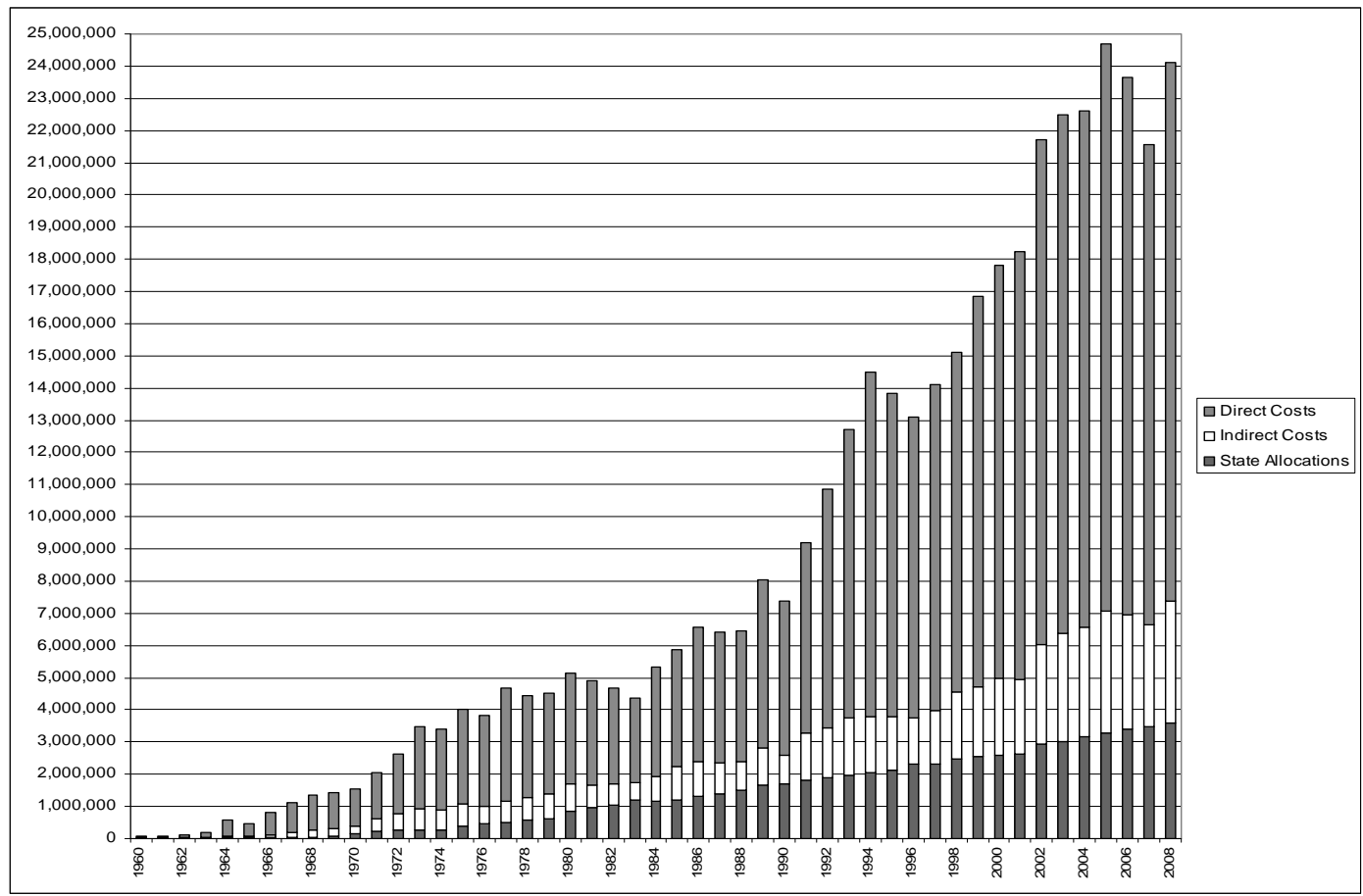

Not surprisingly this graph shows an increase in all three types of funding over time. The university funding for the program (the bottom bar) shows a linear growth and a relatively modest trajectory. An analysis of this trend compared to the other trends shows that the "return on investment" of the LSI 
has changed dramatically since 1990 . In 1990 the LSI generated approximately three external research dollars for every one dollar it received in university support. By early in the 2000s the return on investment had doubled to one dollar in university support for every six dollars in external award dollars generated.

A careful examination of this graph will reveal some other important information. Over the 49 year period represented external award dollars have increased 32 years and decreased 17 years. That is, awards have decreased roughly one-third of the time and increased roughly two-thirds of the time. Furthermore, multiple year decreases have occurred four times. Each of these decreases and increases occurred for various reasons - usually for several different reasons in fact. These explanations vary widely and reflect both national level issues (e.g. overall declines in research funding by some federal programs, or many federal programs as during the early Reagan administration years), and local conditions (e.g. a powerful new program was added to the institute, another program declined due to loss of key investigators, etc). The main point is that over this 49-year period, overall program funding has increased substantially, but in a pattern that might remind the reader of the stock market a generally positive trajectory with lots of temporary declines.

\section{The Present Macro Context}

The performance of a research program should be evaluated in part on the basis of the macro context in which it exists (e.g. the amount of funding available nationally) and the micro context (i.e. the local situation). Both contexts are typically complex. At the macro level, there are a lot of positive indicators that suggest the future for university based research centers should be bright in general. These include:

- Bi-lateral support for science and research in the U.S. Congress

- A high level of support in general for research among the general populace

- The fact that research represents a very small slice of the overall federal budget, which undermines the argument that we are spending too much on it

- Globalization will continue to increase the value of science and research because these are viewed as indispensable necessities to compete effectively

- In recognition of the value of certain types of research (e.g. bioscience), states are getting into the business of supporting research using a variety of mechanisms.

- The death of corporate labs (e.g. the famous Bell Labs) has increased the need and value of university based research as a source of technological innovation capable of driving future business successes

- Private foundations have thrived in recent years and have far more resources to invest in research than they did previously

- Donors like to support "big ideas" (e.g. curing cancer or 
autism) and are giving to

universities for research related

endeavors at record levels.

- And finally, we are faced with

large daunting problems that

require discovery and innovation

(e.g. climate change, the autism

epidemic, etc). In other words -

there is a great need for university research.

There are also a number of caution signs in the macro environment that we certainly need to pay attention to. These include the following:

There is and will continue to be enormous pressures on state and federal budgets due to growing costs for entitlements, defense, and debt service that at the minimum may hold down the growth in research funding.

There are forces that wish to cut the amount of funding that goes for so called "indirect costs". Any successes in this effort could very seriously undermine the research enterprise.

While businesses and foundation are often interested in collaborating with universities and sometimes can be far more flexible and responsive than federal agencies, they can also be far more whimsical in their decision making. This can in turn make them poor partners for long term research support.

Research often requires new and specialized technologies to advance. The cost of these technologies continues to rapidly grow. Start-up, recruitment, and retention packages have soared as a result and there may be no end to this. It may result in the "haves" and "have nots" in terms of broadly competitive research universities. This dynamic could even ultimately decrease the breadth and depth of competition needed for rapid advancement.

Many universities and especially academic medical centers are highly leveraged at present. They have invested massive sums in research buildings and cutting edge technologies. In the kind of 'no growth' or even declining federal support environment that we are presently experiencing, the financial collapse of some research programs may be just around the corner.

Pressures on young investigators are unprecedented. They endure very long apprenticeships, then must get their own R01 or be denied tenure, and then continue to rake in external research dollars to support both their research and often their salary. As a result, the huge investment that goes into training a competitive research scientist can be washed out as people leave the academy for more stable careers.

\section{The Real Dangers}

These lists of positive indicators and caution signs reflect the present complexities of the macro environment. The positive indicators provide some assurance that our long term investments in research centers and infrastructure should pay off in a variety of ways - most importantly in making university research truly relevant to our national and global futures. But ignoring the caution signs would be foolish. What we need to do is view these as challenges to be overcome. Still there can be real dangers in how individual universities respond to these challenges. 
What are some of these "real dangers"? They include the following:

Treating the overall research program of the university and/or individual research centers as "cash cows". This is one of the oldest games around. It happens when administrators view indirect costs generated by external grants as a means to fund other university priorities, including other research priorities. The excessive use of this approach can backfire by undermining the future of the very centers that produce these indirect costs. This in term may limit the long term impact and success of these programs or even lead to their competitive demise.

A variation on the cash cow syndrome is expecting unreasonable growth and return-on-investment from research programs in general and research centers in particular. This tendency was reinforced by the "go-go" (as in "grow-grow") atmosphere of the late 90's during which both the stock market and many university research programs grew at double digit levels for several years. This can and did lead to many high-risk "sure deal" ventures during this period that subsequently crashed.

Probably the biggest danger that can happen over time is the decoupling of the research mission of the university from the academic and service mission. This can happen slowly over time in insidious ways with various hidden dangers. It can create a chasm between schools and academic departments and faculty members that spills over into both graduate and undergraduate training. Then when the "research business" runs into rough seas, other sectors of the university may view the situation as "not their problem". Conversely, when the research mission is well integrated into the broader mission of the university it can clearly have a huge positive impact on both undergraduate and graduate training as well as the service mission.

Failing to provide bridge funding for junior and senior investigators when they go through a downturn in funding. With the current budget crunch at NIH, it can take two full years or more for a grant to be funded simply because of the massive number of outstanding proposals that may be ahead of it in line. At the LSI we have many investigators who eventually have received substantial NIH grants in the last three years, but who were required to submit their grant three times (an original submission, and two revisions). That is, they succeeded in a highly competitive world, but it took them a long time to do it. Our ability to bridge some of these successful investigators was in certain cases the key to keeping them successful and their research careers moving forward.

Cutting back core support from centers during short term declines. As the 49 year track record of the LSI demonstrates, overall funding goes down at times. Stable core funding support during these down periods is as much and possibly more important than during up periods. In a sense the message here is the same one given endlessly to investors in the stock market - DON'T invest at all unless you have the stomach to weather some down times. At the LSI we have benefited in general from a long term investment philosophy of our university. Of course 
this philosophy could change at any time. It's definitely not written in stone. So it needs to be reviewed and reconfirmed from time to time. This doesn't mean that core funding shouldn't be cut to centers. In fact, centers that under- perform by reasonable "context sensitive benchmarks" should be carefully evaluated and potentially reorganized or shut down.

\section{Lessons from the Past for the Future}

The beauty of a "mature" research program with a relatively long history like ours is that it has been through good times and bad times. Over this period certain strategies have been identified that seem to make a difference in the long haul. These strategies, coupled with wise practices by our university research administration, have clearly played a role in our success over the years. But it's important to point out that both are necessary and neither by itself is sufficient to guarantee success over the long term. So here is what we've learned over from our lengthy history of success.

Things go up and things go down. If they go up roughly twice and much as they go down, you are probably doing something right.

Diversify your portfolio. We have several different funding sources and at different times, each has been a larger or smaller contributor to our success. In 1969, our external grant budget came from only two federal sources, the NIH and the Department of Health and Human Resources and 80\% came from NIH. In 1979, our external grant budget came from four sources (NIH, HHS, the US Department of Education, and the
State of Kansas). By 1989 various foundations had been added to this mix and we now had five basic sources). In 1999 and 2008 we had 6 different sources. Over time our most constant source of external funding has been the $\mathrm{NIH}$. Even so, as a percent of our total external funding they have varied from a high of $80 \%$ (1969) to a low of $32 \%$ (1999). They presently account for $48 \%$. Like a good stock portfolio, diversification has helped us weather all sorts of bumps in the road over our long history.

Build from your strengths, stick to your mission, but don't forget that the rule of the jungle is that you evolve or die! We can't be world class in everything. But we can be world class in everything we choose to do. To do this, we must build and maintain strength areas and we have generally stuck to this approach over the past 50 years. The reason for this is Darwinian - we compete most successfully in our strength areas, and we recruit our best scientists in these areas, and so these have remained our strengths.

Compete, compete, and compete. Our strongest areas have generally been those in which we had to compete against highly talented scientists on a national level. Competition sharpens ideas and improves research, and thus leads to greater impact. Over time it winnows out the weaker ideas, the incomplete ideas, and the inadequate methods. It is fundamental to long term success.

Persist, persist, and persist. This is a long term game, a marathon of sorts. Failure is a necessary part of good science and is to be expected and even 
welcomed because it ultimately opens the path to success. The same is true in terms of succeeding in the highly competitive world of external research funding.

Encourage, support, and reward collaboration at all levels. Collaboration is anything but easy. But it often leads to better science and increasingly is necessary for scientific success in a wide array of domains.

Focus on the impact of the work. On one level scientists are deeply skeptical. The rules of science require them to be. But they are also romantics in a sense. Their work is about the creation of new knowledge, be it basic or applied knowledge. This is ultimately a noble pursuit that really can lead to improvements in the human condition and more. This is in fact the real work.
Losing sight of this destroys the heart and soul of the scientific enterprise.

In summary, universities face very challenging conditions in terms of building the future of their research enterprises. This has mostly been the case in the past as well and so there is nothing really special about the current period. As usual, securing our futures requires that we learn from the successes and failures of the past. Fortunately there have been plenty of both. Failure to attend to the lessons of the past could be the biggest source of risk in the present environment.

\section{References}

Schiefelbusch, R.L. \& Schroeder, S.R. (2006).

Doing Science and Doing Good. Baltimore:

Brookes Publishing. 